\title{
Modeling and Numerical Validation of Stress-Strain Curves of Maraging Steels, Grades 300 and 350 Under Hydrogen Embrittlement
}

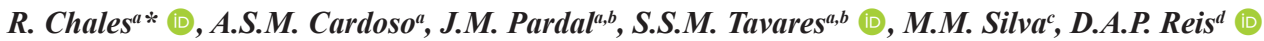 \\ ${ }^{a}$ Universidade Federal Fluminense (UFF), Programas de Pós-Graduação em Engenharia Mecânica \\ (PGMEC) e Montagem Industrial, Niterói, RJ, Brasil \\ ${ }^{b}$ Centro Federal de Educação Celso Suckow, Programa de Pós-Graduação em Ciências dos Materiais, \\ Rio de Janeiro, RJ, Brasil \\ 'Instituto Tecnológico de Aeronáutica - ITA, Materiais e Processos de Fabricação, São José dos \\ Campos, SP, Brasil \\ ${ }^{d}$ Universidade Federal de São Paulo - UNIFESP, Instituto de Ciência e Tecnologia, São José dos \\ Campos, SP, Brasil
}

Received: September 20, 2020; Revised: February 23, 2021; Accepted: March 2, 2021

\begin{abstract}
Maraging steels are ferrous alloys with $\mathrm{Ni}, \mathrm{Co}, \mathrm{Mo}$, and Ti additions. These materials are a special class of ultra high mechanical strength steels with wide and special applications in strategic areas, which makes their knowledge very valuable. Computational advances allowed to analyze the behavior of these materials numerically, using the finite element method and developing mathematical models that can represent numerically its mechanical behavior. The present work has the objective of surveying the mechanical properties of maraging steels 300 and 350 by slow strain rate tensile (SSRT) tests, after the solution treatment at $1183 \mathrm{~K}$ for $1 \mathrm{~h}$. Additionally, it was evaluated the hydrogen embrittlement in samples tested by SSRT under cathodic protection with a potential $-1.2 \mathrm{VSCE}$ in $3.5 \% \mathrm{NaCl}$ solution. The study was complemented with detailed fractographic analysis. This work also presents the analysis of representative models by use of Hollomon, Swift, Voce and coupled Swift-Voce equations to describe the strain-hardening behavior. Compared to the others, the Voce's model was the one which best fitted the experimental results, with values of $\mathrm{R}^{2}$ higher than 0.992 . Through the variation of the chemical composition found in the different grades of maraging steels, this work contemplates the creation of a generalized Voce model based on the variation of the Ti content. The work concludes presenting the generalized Voce model proposed and a numerical analysis of the SSRT results with a good accuracy of the strain-hardening response.
\end{abstract}

Keywords: Maraging steel, slow strain rate test, embrittlement effect, modelling, finite element analysis.

\section{Introduction}

Maraging steels have excellent mechanical properties and recent studies point to significant improvements in their specific properties with the combination of surface treatments available for numerous purposes: protection against surface corrosion, resistance to embrittlement by hydrogen, increase in hardness, reduction wear, among other applications ${ }^{1-4}$.

In the solution treatment (ST) condition, maraging steels exhibit great ductility and toughness as a result of the formation of a body-centered cubic (BCC) martensitic structure. This treatment is performed above the final temperature of the martensite to austenite transformation, remaining long enough to place all the alloying elements in solid solution, besides promoting residual stress relief ${ }^{5,6,7}$.

The embrittlement process is manifested by the decrease in the ductility of metals ${ }^{8}$ and studies performed by Tsay ${ }^{9,10}$ suggest that the presence of atomic hydrogen in the metal

*e-mail: rodrigochales@id.uff.br surface can induce the phenomenon of embrittlement. The hydrogen interacts resulting in modifications of the mechanical properties and leading to the occurrence of brittle fracture in the metals, especially in the ultra-high strength as the maraging steels. Several studies have been done detailing the harmful effects that the presence of hydrogen infers on the final mechanical properties of the material, such as area reduction, elongation, strength limit and fracture characteristics ${ }^{4,7,8}$, important data to be used in mathematical models.

The influence of titanium on plasticity and ductility was investigated by Men'shikova ${ }^{11}$ using samples from different titanium concentrations $(0.12$ and $0.57 \%)$. After analysis, it was observed that increasing the titanium content of maraging steels increases its strength and decreases plasticity and ductility. Studies suggest this element is the most effective strengthening agent in maraging steels. Therefore, efforts may be employed to generate models which describes the strain-hardening behavior in these materials. 
Aiming to demonstrate the importance of using numerical models and methods to describe the hardening behavior of materials, some authors like Huang ${ }^{12}$ developed the relationship between the flow stress and the dislocation density quantity can be described by models. The strainhardening and softening behavior was analyzed in detail by Kocks-Mecking type plots. The experimental flow stress was found to be in close agreement with the calculated, which confirms that the model developed herein can represent the flow behaviors of the metals effectively. Nieto-Fuentes et al. ${ }^{13}$ explained that physical metallurgy and its defects like dislocation-based constitutive models are widely used to predict the plastic behavior of metallic materials, and the ratio of adiabatic thermomechanical conversion is known, the stress-strain-temperature relationship can be estimated. In these studies, we can calculate the stored energy and the temperature rise during dynamic plastic deformation using a micromechanical model. Then this research is required because show that the computational advance is very important in actual scientific studies. Great efforts have been employed in constitutive models able to predict the strain-hardening behavior of the materials. These models are used to describe the material numerically, providing the ability to perform numerical analysis for widely engineering problems. Hollomon, Swift, Voce and coupled models are approached by different authors, showing their applicability and precision for different materials ${ }^{14-24}$.

The importance of the correlation of the transformation of austenite in martensitic phase into steel can be correlated with models studied by Levitas and Roy ${ }^{25}$ the finite-element method is an excellent tool for studying temperature-induced phases (PTs) correlating phases and energetic crystal. The developed requirements and approach are applicable to various temperature-induced phases transformations between multiple solid and liquid phases and can be elaborated for temperatureinduced phases transformations induced by mechanical and electromagnetic fields, diffusive PTs, and the evolution of multi-grain and multi-twin microstructures. Levitas et al. ${ }^{26}$ showed that a phase-field theory of transformations between martensitic variants and multiple twinning within martensitic variants is developed for large strains and lattice rotations, than a finite-element approach is developed and applied to the solution of a number of examples of twinning and combined austenite-martensite and martensite phase transformations (PTs) and nanostructure evolution. A similar approach can be developed for reconstructive, electric, and magnetic PTs, confirming the good application of numerical methods to describe the behavior of materials.

Displacement-based hardening model can be correlated with models researched by $\mathrm{He}$ and $\mathrm{YaO}^{27}$ that showed a dislocation density based in constitutive model should be able describe the viscoplastic behavior of lead free solder joints. The inelastic deformation is predicted based on the mobile dislocation density, and the immobile dislocation density is adopted to predict the evolution of yield surface. An implicit algorithm is employed to determine the stress evolution for arbitrary paths. The developed constitutive model is programmed into the finite element analysis to simulate the viscoplastic deformation of solder joints. Solomon et al. ${ }^{28}$ showed that through combination of high-resolution characterization, density functional theory calculations, and finite-element elasticity studies, we demonstrate that the strengthening phase is thermodynamically stable at low temperatures, as opposed to metastable as, highlighting the importance of using numerical methods and mathematical models.

This paper presents the hydrogen embrittlement effects on mechanical properties of maraging steels 300 and 350 in ST condition. The results were obtained by slow strain rate tests (SSRT) and, complementary, data-processing were performed and the average curves were obtained for each condition. Additionally, constitutive models of Hollomon, Swift and Voce were used to describe the plastic behavior using the coefficient of determination $\left(\mathrm{R}^{2}\right)$ to evaluate the fitting of experimental values. Using linear approximations, generalized mathematical models were obtained relating the mechanical properties of the maraging as a function of the titanium content. Finally, using ANSYS software, the SSRT was performed numerically and the results by finite element analysis (FEA) were compared, presenting the accuracy of the models determined in this study.

The purpose of this study is to correlate the behavior of mechanical properties of solution treated maraging 300 and 350 steels under several hydrogen charged conditions with the application of constitutive hardening models allowing an improvement about the knowledge from these alloy's behavior in strategic operations.

\section{Materials and Methods}

The materials employed in this work were the ferrous alloys with $18 \%$ Ni class 300 and 350 known as maraging steels, with chemical compositions shown in the Table 1. The chemical compositions are in accordance to the standard AMS 6515A14. The material was received in the form of a bar and analyzed for the following elements by Coupled Plasma Source Optical Emission Spectrometry (ICP-OES). The elements carbon, sulfur, hydrogen and nitrogen were analyzed and their contents were obtained by direct combustion.

Solution treatments (ST) were performed in both materials in a furnace with atmosphere controlled by Argon at $1183 \mathrm{~K}$ for $1 \mathrm{~h}$, followed by air cooling to room temperature. After this, eighteen (18) specimens for slow strain rate test (SSRT) were obtained by machining in accordance with the ASTM E8 / E8M-11 standard, with $4 \mathrm{~mm}$ of diameter and $16 \mathrm{~mm}$ of gauge length. SSRT were performed based on ASTM G129-00 $0^{29}$ recommendation employing $2.0^{*} 10^{-4} \mathrm{~mm} \cdot \mathrm{s}^{-1}$ of test speed with $45 \mathrm{kgf}$ of preload. This preload was applied before starting the test, in order to calibrate the data acquisition

Table 1. Chemical composition of the maraging steels 300 and 350 studied (wt.\%).

\begin{tabular}{ccccccccc}
\hline Material/Identification & $\mathbf{C}$ & $\mathbf{N i}$ & $\mathbf{C o}$ & $\mathbf{M o}$ & $\mathbf{T i}$ & $\mathbf{A l}$ & $\mathbf{M n}$ & $\mathbf{F e}$ \\
\hline Maraging steel 300 (M300) & 0.0043 & 18.28 & 9.41 & 4.73 & 0.732 & 0.071 & 0.027 & balance \\
\hline Maraging steel 350 (M350) & 0.0023 & 17.65 & 11.65 & 4.69 & 1.44 & 0.0065 & 0.021 & balance \\
\hline
\end{tabular}


and avoid specimen slips during the initial loading tests. Thus, tests were performed on ST specimens of maraging 300 (M300) and maraging 350 (M350) conventionally in the air (Air), in saline environment generating hydrogen cathodically $24 \mathrm{~h}$ prior and during the test $(24 \mathrm{HE})$ and only during the test (HE). The tensile machine and the electrolytic cell used to perform the hydrogen embrittlement environment for the testing are presented on Figure 1. A potentiostat was used for the hydrogen charging process. The specimens were fixed inside a cell attached to the machine test. The solution used was $3.5 \% \mathrm{NaCl}$ under a simultaneous application of a cathodic potential of $-1.2 \mathrm{~V}_{\mathrm{SCE}}$ in both cases. The process was performed at low current density of $0.32 \mathrm{~A} . \mathrm{m}^{-2}$. Table 2 shows the identification of the tests carried out in different environments for both M300 and M350 on ST condition, emphasizing that each condition was carried out in triplicate.

Some deviations as the rigidity of the test machine, the initial preloading and the small slips during the test were considered and removed by processing the initial data. Based on the tests performed, the rigidity of the machine was obtained $(40 \mathrm{Ga} \pm 1 \mathrm{GPa})$ and the respective correction in elastic and plastic fields were performed eliminating distortions of the test apparatus.

From SSRT curves, the respective true stress-strain curves $\left(\sigma_{r} \mathrm{X} \varepsilon_{r}\right)$ were constructed through the Equation 1 and Equation 2.

$\varepsilon_{r}=\ln \left(\varepsilon_{c}+1\right)$

$\sigma_{r}=\frac{P}{S_{0}} *\left(\varepsilon_{c}+1\right)$

Where $\varepsilon_{c}$ is the engineering strain, $\mathrm{P}$ is the force applied on test and $\mathrm{S}_{0}$ is the initial section area of the specimens.
The curves $\sigma_{r} \times \varepsilon_{r}$ were adjusted for their average curves taking into account the Equation 3.

$x_{n}=\frac{\sum_{i=1}^{k} p_{n}^{i}}{k}$

Where $\mathrm{n}$ is the number of values obtained during SSRT and $\mathrm{k}$ the number of specimens evaluated in each condition (3). Thus, the average curves for each condition were analyzed.

The Hooke's law is applied for the Ferrous alloy $18 \% \mathrm{Ni}$ grades 300 and 350 considering well-defined linear behavior typical for these steels and is represented by the Equation 4.

$\{\sigma\}=[E] *\{\varepsilon\}$

Where the $\sigma$ is the stress, $\mathrm{E}$ is the modulus of elasticity of the material and $\varepsilon$ its specific deformation. The tensile modulus considered is 190 and $200 \mathrm{GPa}$ for M300 and M350, respectively, in accordance with the AMS 6515 standard.

\subsection{Modelling}

Considering the ferrous alloy, once the elastic limit of the material has been reached, the plastic deformation occurs followed by a hardening where the stress must be continuously increased in order to continue producing plastic deformation. For a multiaxial case, the function that describes the yield surface of the material can be written by the Equation 5 .

$$
f\left(\sigma_{i j}, K_{i}\right)=0
$$

Where Ki represents one or more material hardening parameters that will change during plastic deformation and determine the evolution of the yield surface. For a material with no hardening, the function can be expressed as the Equation 6.
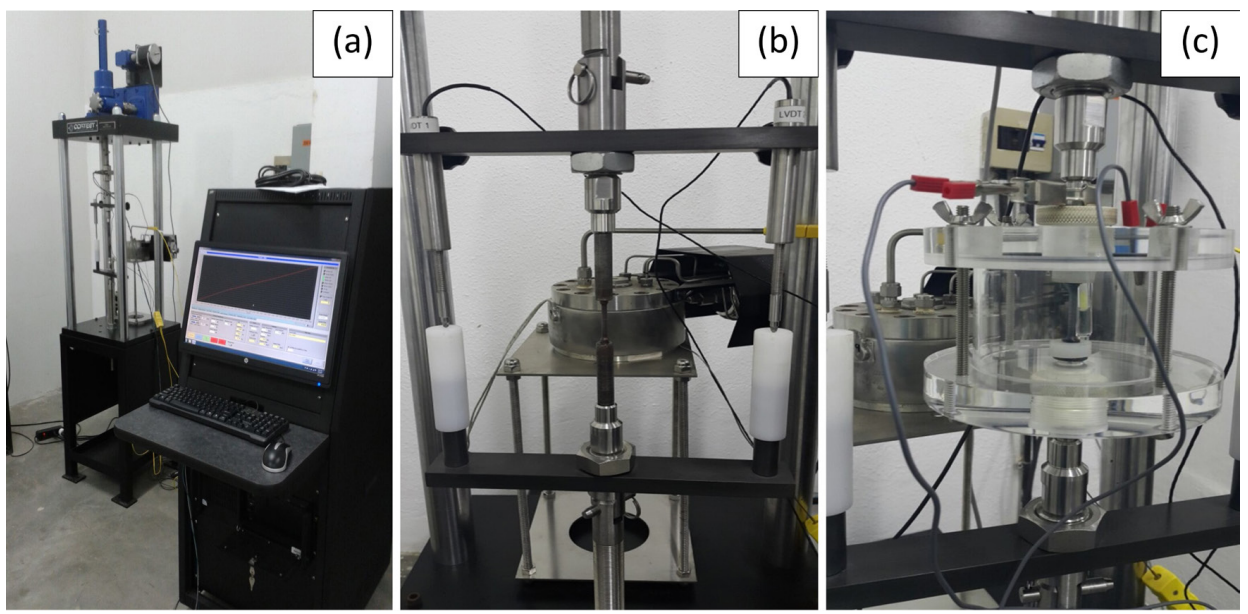

Figure 1. (a) Cortest's Constant Extension Rate Test machine used for testing samples in (b) air and under (c) hydrogen embrittlement using electrolytic cell.

Table 2. Categorized of specimens tested on SSRT.

\begin{tabular}{cccc}
\hline Material & \multicolumn{3}{c}{ HEAT TREATMENT / ENVIRONMENT } \\
\cline { 3 - 4 } & \multicolumn{2}{c}{ Solution Treatment (ST) } \\
\hline Maraging 300 (M300) & & Air* & HE* \\
\hline Maraging 350 (M350) & & & $24 \mathrm{HE}^{*}$ \\
\hline
\end{tabular}

(*) Performed in triplicate for each condition 


$$
f\left(\sigma_{i j}, 0\right)=f_{o}\left(\sigma_{i j}\right)
$$

The isotropic hardening is when the material continues with its flow surface, but it expands with increasing stress. The isotropic hardening can be written by the Equation 7 .

$$
f\left(\sigma_{i j}, K_{i}\right)=f_{o}\left(\sigma_{i j}\right)-K=0
$$

Where $f_{o}\left(\sigma_{i j}\right)$ is the function that describes the shape of the material flow surface and $\mathrm{K}$ is the hardening parameter responsible for the surface expansion. For SSRT, the specimens are submitted to a continuous unidirectional deformation process until their rupture, being better represented by an isotropic hardening model with expansion of its yield surface $^{14,30}$. The hardening function of Von Mises was used, being expressed by the Equation 8 .

$$
f\left(\sigma_{i j}\right)=\frac{1}{\sqrt{2}} \sqrt{\left(\sigma_{I}-\sigma_{2}\right)^{2}+\left(\sigma_{2}-\sigma_{3}\right)^{2}+\left(\sigma_{3}-\sigma_{I}\right)^{2}}-Y
$$

Where $Y$ is the stress performed by the uniaxial tensile testing, and $\sigma_{1}, \sigma_{2}$ and $\sigma_{3}$ are the principal stresses. Experiments performed with metals confirmed that the increase of plastic deformation acts normal to the hardening surface of the material. This behavior is described as associative flow, being expressed by the Equation 9 .

$$
d \varepsilon_{i j}=\dot{\lambda} \frac{\partial f\left(\sigma_{i j}\right)}{\partial \sigma_{i j}}
$$

Where $\dot{\lambda}$ is the material hardening parameter and the function $f\left(\sigma_{i j}\right)$ is defined by the plastic incompressibility of the material, which is the function that describes the evolution of the yield surface through the hardening.

\subsection{Strain-hardening models}

Based on an isotropic hardening criteria, Hollomon's model is a simplified mathematical model that can accurately describe the hardening behavior of the material obtained at the macroscopic level through tensile tests ${ }^{14,17}$. Through several studies, it was clearly perceived the good relationship of this model with the stress hardening behavior in metals. The Hollomon power law equation is given by Equation 10, where $\varepsilon$ is the true strain, $\mathrm{n}$ is the strain hardening exponent and $\mathrm{k}$ is the strength coefficient.

$$
\sigma=k^{*} \varepsilon^{n}
$$

The Swift model ${ }^{18}$ is similar to the Hollomon's model, but takes into account separately the strains caused in elastic and plastic period. This equation is described by Equation 11 and proposes another power-law equation, introducing the parameter $\varepsilon_{0}$ which accounts for a pre-strain.

$$
\sigma=k *\left(\varepsilon_{0}+\varepsilon\right)^{n}
$$

The Voce is an isotropic hardening model with its formulation based on exponential form. The model used is the variation of linear hardening models where an exponential saturation term is added to the linear term, assuming that the hardening will eventually reach a maximum point in its stress. This model responds to what is indicated in Equation 12, where
$\sigma_{S}$ is the elasticity limit, $\varepsilon_{p}$ is material's plastic strain and parameters that define the material hardening represented by $R_{o}, R_{\text {inf }}$ and b coefficients. This model is suitable for materials with little hardening and high plasticity ${ }^{14,19}$.

$$
\sigma=\sigma_{S}+R_{o} \varepsilon_{p}+R_{\text {inf }}\left(1-e^{-b^{*} \varepsilon_{p}}\right)
$$

The Swift-Voce coupled model represented by Equation 13 combines the parabolic equation proposed by Swift with the exponential term formulation proposed by Voce.

$\sigma=(1-\alpha) * k^{*}\left(\varepsilon+\varepsilon_{o}\right)^{n}+\alpha *\left(\sigma_{S}+R_{o} \varepsilon_{p}+R_{\text {inf }} *\left(1-e^{-b^{*} \varepsilon_{p}}\right)\right)$

Where $\alpha$ is a measure of the contribution of each model which a value of 1 represents pure Swift behavior and a value of 0 describes pure Voce model behavior. When $\varepsilon_{o}$ is zero, the equation is reduced by the Hollomon-Voce coupled model proposed by Sung ${ }^{31}$.

\subsection{Generalized hardening model by the titanium composition}

Studies performed by Men'shikova ${ }^{11}$ shows that titanium acts as an important hardening agent in this alloy. The Ti is used in different materials as an austenitic stabilizer element and affect the main hardening mechanism, where the hardening process for low carbon contents is mainly governed by martensitic transformation ${ }^{32}$. The increase in titanium content acts directly on its strain-hardening behavior. Using the M300 and M350 specimens, it is possible to estimate the strain-hardening behavior at intermediate concentrations of titanium present in this alloy. Based on this, the generalized Voce model as a function of the titanium content can be defined, assuming the following conditions:

1. Titanium is considered the main element that significantly alters the mechanical behavior of the material;

2. The titanium content must be equal to or between the contents presented in M300 and M350;

3. The variation in the titanium contend reflects a direct linear variation between the strain-hardening curves.

The titanium mass contents used for M300 and M350 were reported in Table 1. Between these conditions, intermediate curves are assigned assuming a linear relationship with the titanium content present and obtaining the Voce model parameters to predict these curves. To get this generalized non-linear isotropic hardening model, the new coefficients can be fitted as a function of the titanium content in the alloy, through the Equation 14-17.

$$
\begin{aligned}
& \sigma_{S F}=\sigma_{S T i}(T i) * \sigma_{S} \\
& R_{O F}=R_{O T i}(T i) * R_{o} \\
& R_{\text {inf.F }}=R_{i n f . T i}(T i) * R_{\text {inf }} \\
& b_{F}=b_{T i}(T i)^{*} b
\end{aligned}
$$

Where $\sigma_{S T i}(T i), R_{\text {oTi }}(T i), R_{\text {inf } . T i}(T i)$ and $b_{T i}(T i)$ are functions that describe the value as a function of the titanium content 
present in the alloy. Therefore, the generalized Voce model can be expressed by the Equation 18 .

$$
\begin{aligned}
& \sigma=\sigma_{S T i}(T i) * \sigma_{S}+R_{O T i}(T i)^{*} R_{o} * \varepsilon_{p}+ \\
& R_{\text {inf. } . T}(T i) * R_{\text {inf }} *\left(1-e^{-b_{T i}(T i)^{*} b^{*} \varepsilon_{p}}\right)
\end{aligned}
$$

\subsection{Finite element analysis (FEA)}

Using the finite element method (FEM), it was performed the numerical representation of the SSRT with the generalized equation obtained. For this, the ANSYS commercial software based on the finite element method was employed to assign all boundary conditions as well the strain-hardening models used to predict the material behavior.

The specimen and boundary conditions were numerically modeled following the same physical conditions as the bench tests. To represent the elasto-plastic behavior, an isotropic elasticity model and a nonlinear isotropic hardening model (Voce) were adopted. With a mesh size of approximately $1 \mathrm{~mm}$, the finite element chosen is a high order element (SOLID186), composed of 20 nodes and widely used in the discretization of solid structures ${ }^{17}$. This element has three degrees of freedom in each node and, in its formulation, has plasticity, stress hardening, large deflections and great deformation capacity. During element assignment, care was taken to ensure the quality of the mesh generated avoiding element distortion, void volumes and truncations.

\section{Results and Discussion}

From SSRT tests performed in triplicate, Figure 2a presents the stress-strain curves of ST specimens of maraging 300 (M300). Figure 2(b) shows the results obtained for ST specimens of maraging 350 (M350).

After SSRT, the results were processed, eliminating residual errors from test apparatus. The elastic field, considered by Equation 4, was fitted using the elasticity modulus (E) of maraging steels 300 and 350 from AMS 6515 standard. The rigidity of the machine $(40 \mathrm{Ga} \pm 1 \mathrm{GPa})$ was found and eliminated from the results. The true stress-strain curves were obtained using Equation 1 and Equation 2. From Equation 3, the respective average curves were got and plotted. Figure 3 presents the corrected average stress-strain curves for each ST specimen of maraging 300 and 350 in air and under HE conditions, after data processing.

The mechanical properties were obtained and arranged in the Table 3 for each respective condition. The resilience and toughness results were obtained directly by the area of the curves for each condition.
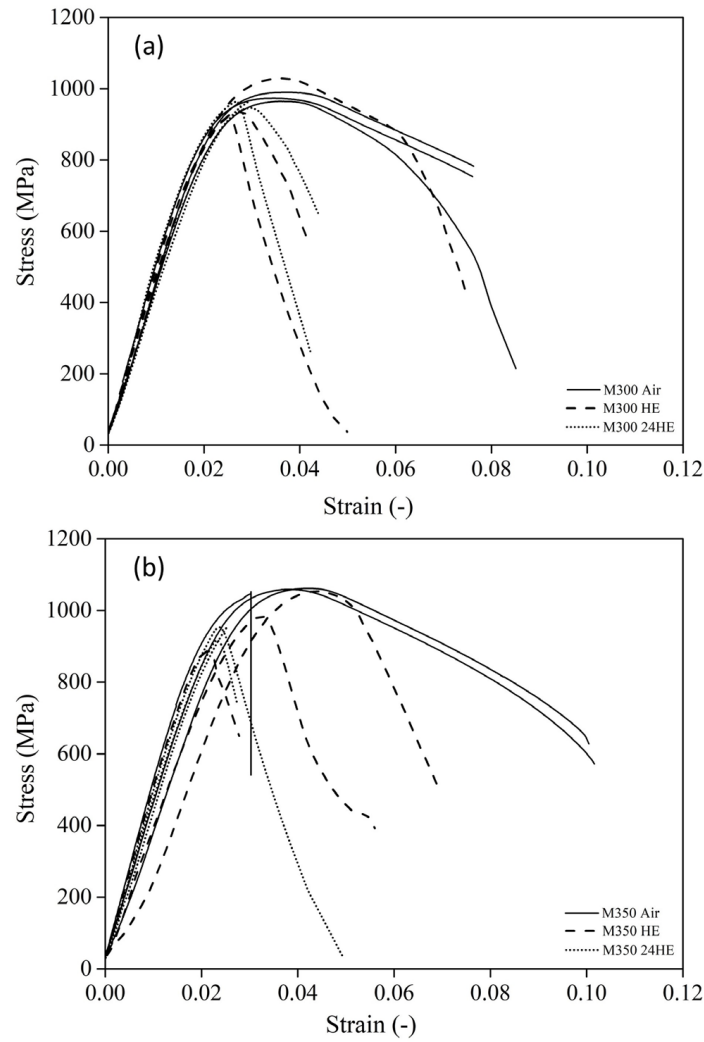

Figure 2. SSRT stress-strain curves of solution treatment specimens of maraging (a) M300 and (b) M350 in air and under HE conditions.

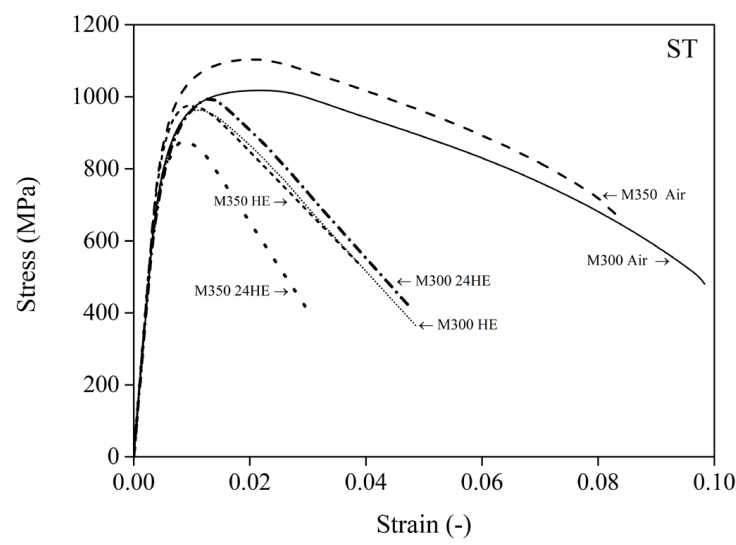

Figure 3. Average stress-strain curves for ST specimens of maraging $\mathrm{M} 300$ and M350 in air and under HE conditions after data processing.

\begin{tabular}{|c|c|c|c|c|c|c|}
\hline Material & $\begin{array}{l}\text { Yield Strength } \\
\text { (YS) }\end{array}$ & $\begin{array}{c}\text { Ultimate Tensile } \\
\text { Stress (UTS) }\end{array}$ & Strain, \& & Resilience & Tenacity & $\begin{array}{c}\text { Reduction of } \\
\text { area (RA) }\end{array}$ \\
\hline- & $M P a$ & $\begin{array}{c}P a \\
\end{array}$ & $\%$ & $J / m^{3}$ & $J / m^{3}$ & $\%$ \\
\hline M300 Air & $873.47 \pm 14.7$ & $1012.29 \pm 14.34$ & $9.15 \pm 1.18$ & $3.54 \pm 0.11$ & $73.34 \pm 12.2$ & $43.8 \pm 6.6$ \\
\hline M300 HE & $871.64 \pm 62.37$ & $995.54 \pm 71.02$ & $4.86 \pm 1.6$ & $3.53 \pm 0.36$ & $35.2 \pm 18.66$ & $8.7 \pm 3.1$ \\
\hline M300 24HE & $859.87 \pm 47.21$ & $1000.49 \pm 25.58$ & $4.77 \pm 2.26$ & $3.44 \pm 0.32$ & $35.52 \pm 17.58$ & $4.8 \pm 2.6$ \\
\hline M350 Air & $963.95 \pm 14$ & $1103.89 \pm 5.34$ & $8.4 \pm 0.32$ & $4.1 \pm 0.08$ & $77.63 \pm 1.79$ & $37.5 \pm 4.5$ \\
\hline M350 HE & $933.13 \pm 38.08$ & $1007.06 \pm 97.85$ & $3.87 \pm 1.85$ & $3.86 \pm 0.29$ & $29.96 \pm 16.44$ & $12.8 \pm 18.4$ \\
\hline M350 24HE & $840.1 \pm 142.21$ & $903.45 \pm 189.67$ & $3.08 \pm 1.73$ & $3.32 \pm 0.84$ & $18.87 \pm 9.91$ & $6.1 \pm 8.0$ \\
\hline
\end{tabular}

Table 3. Mechanical properties and their respective measurement deviations obtained for each condition tested. 
Based on the maraging steel specimens tested, the results show that the solution treatment in maraging 300 and 350 steels provides, as a general result, samples showing some ductility during the tests. The samples show a ductile behavior with a well-defined region. After the beginning of necking, there is a local stress increase resulting through the geometric profile of the zone, thus characterizing the fracture in this region.

In air environment, the M350 specimens on ST condition have, in general, $9 \%$ higher UTS when compared to the results obtained for the M300. A slight reduction in its elongation is also observed when the M350 is compared to M300. One of the major factors associated with this behavior is the increase in the titanium content between these alloys. These values are similar to those reported in the literature for maraging 350 steel $^{33,34}$.

The solution treated samples remain with the highest percentage elongation results compared to the samples in hydrogen embrittlement environment. The largest deviations obtained for the samples in $3.5 \% \mathrm{NaCl}$ solution can be correlated to the induced embrittlement of the samples. Although all samples showed some ductility, the $\mathrm{NaCl}$ solution-tractioned samples underwent hydrogen embrittlement, thus presenting a reduction of their ductility compared to the air-tested samples. The results suggest that the weakening potential of embrittlement is related to the diffusion of hydrogen on samples. This result can be explained according to studies reported by $\mathrm{TSAY}^{9}$, using the same diffusivity coefficient $\mathrm{D}$ equal $8 \times 10^{-12} \mathrm{~m}^{2} / \mathrm{s}$, where hydrogen showed greater diffusivity in 24HE samples when compared to HE. In maraging 300 steel studied by SANTOS $^{7}$ the reduction of elongation was also observed for HE conditions. The embrittlement of the samples caused a decrease in their ductility with little change in the yield limit of the material ${ }^{8}$.

Figures 4 and 5 shows a fractographic view of fractured specimens ST tested in air and in HE. For the $24 \mathrm{HE}$ condition, the behavior of micro and macromechanism are similar to those reported by the HE condition (Figure 5).

Figures $4 \mathrm{a}$ and $\mathrm{b}$, tested in air, show that the specimens exhibited extensive plastic deformation with a neck formation surrounded by a shear lip which is typical of ductile fracture. In contrast, in the specimens tested in HE (Figure 5) a fragile fracture macromechanism was observed, with $45^{\circ}$ rupture, step formation and low area reduction.

On Figure 4, the fractographic specimens for both ST alloys by air shows the specimens suffered a fracture with ductility (dimples) characteristics with high strain and a general morphology showed a cup and cone type of failure. The equiaxed dimpled rupture surrounded by shear lips (characteristic of ductile fracture) was observed in a higher magnification image like the Reis et al. studies ${ }^{35}$.

On Figure 5, the fractography of ST specimens tested in $\mathrm{HE}$ environment reveal the presence of intergranular (Figure $5-\mathrm{b} 2$ ) and transgranular cracks (Figure 5 -
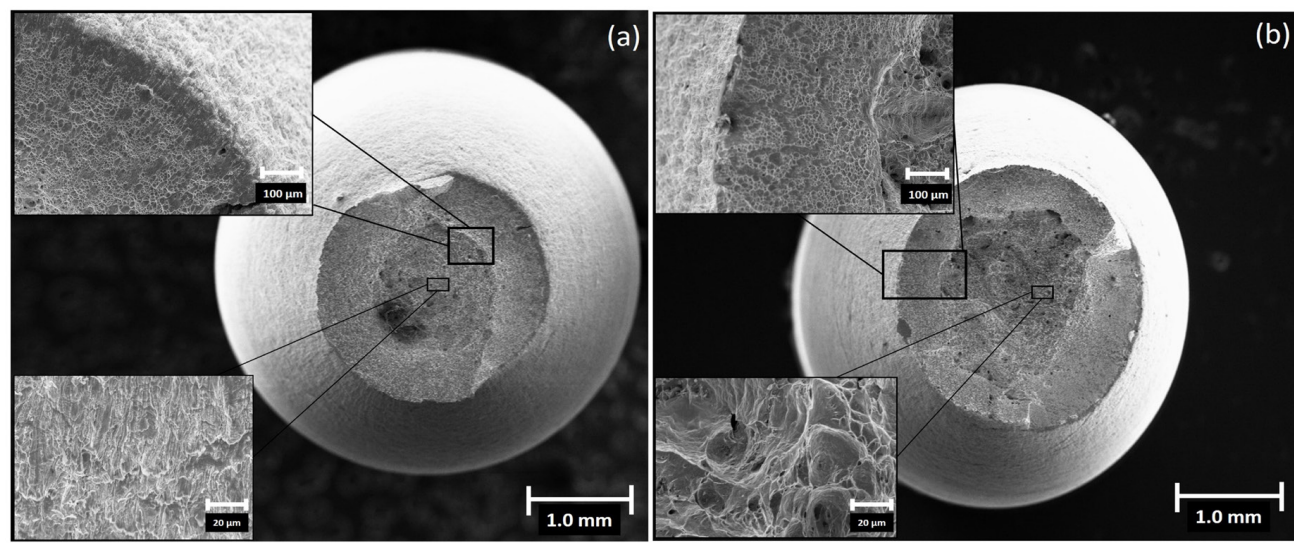

Figure 4. Fractography of ST specimens in air environment of maraging (a) M300 and (b) M350.
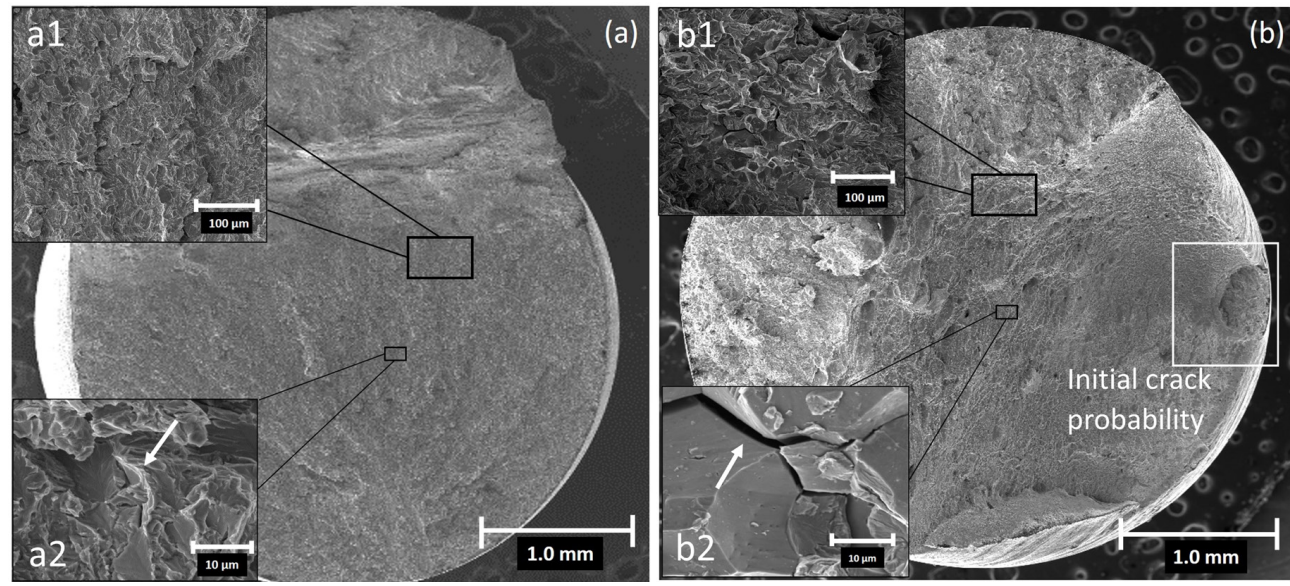

Figure 5. Fractography of ST specimens in HE environment of maraging (a) M300 and (b) M350. 
a2) with rupture characteristics following the grain contours, presenting fracture at $45^{\circ}$ in relation to the direction of the uniaxial tractive load, with cleavage region (Figure $5-\mathrm{a} 2, \mathrm{~b} 1$ ) following by strain reduction of these specimens. Wang et al. ${ }^{36}$, demonstrated that hydrogen-induced cracks propagating along the grain boundaries are a resulting of hydrogen concentration in these regions.

\subsection{Curve fitting results}

Once the elastic limit of the material has been reached, the plastic deformation occurs, followed by a hardening where the stress must be continuously increased in order to continue producing plastic deformation. The nonlinear models of plasticity approached were used to represent mathematically the hardening of the material up to its limit of rupture, where the sample stresses.

The generalized reduced gradient (GRG) algorithm is employed to solve nonlinear optimization problems in which the aim function can have nonlinearities of any nature ${ }^{19,21,37}$. This method was used to solve the convergence models, finding the best approach parameters. Using the GRG through Excel software, it's obtained the coefficients that determine the Hollomon, Swift, Voce and coupled Swift-Voce models for each condition analyzed using Equation 10-13. The results considered the average curves corrected and take into account until the formation of the neck. Figure 6 shows the curve fitting employed for Hollomon, Swift, Voce and coupled Swift-Voce models to predict the strain-hardening of ST maraging steels M300 and M350 in air. Figure 7 presents the curve fitting results for the HE environment and Figure 8 presents the results for the $24 \mathrm{HE}$ testing condition. From Figures 6 to 8 , the best fit parameters which describes each model were disposed on the Table 4.

Table 5 presents the coefficient of determination $\left(\mathrm{R}^{2}\right)$ values for Hollomon, Swift, Voce and Swift-Voce coupled model after fitting curves presented on Table 4. The SwiftVoce coupled model presented more robustness and precision when compared to the other models, reaching $\mathrm{R}^{2}$ values up to 0.992 . The Voce model also presented good prediction results, with higher precision than Hollomon and Swift models reaching $\mathrm{R}^{2}$ up to 0.992 . Hollomon and Swift results presented the lowest values of $\mathrm{R}^{2}, 0.990$ and 0.940 , respectively. The Voce model presents similar results but greater simplicity when compared to the Swift-Voce coupled model.

The effectiveness of the models presented has also been studied by other authors, reporting similar results on predicting the strain-hardening behavior ${ }^{16,20,23,24}$.

Raymond ${ }^{23}$ used the Hollomon model to describe the strain-hardening behavior in metals, presenting results with good accuracy. The Hollomon, Swift and Voce models were also compared by $\mathrm{Cao}^{38}$. The author compared the fitting of the models for five different metallic alloys and concluded the Voce presented the best fitting results, with $\mathrm{R}^{2}$ up to 0.991 . Comparing these three typical constitutive equations, Voce model has also presented the best equation to estimate the yield (YS) and ultimate tensile strength (UTS).

Vadayar $^{39}$ also used the Voce model to predict the behavior of maraging steel grade $\mathrm{C} 250$ under cold flow forming and aged conditions. The author presented the best fit parameters with values of $\mathrm{R}^{2}$ between 0.993 to 0.999 among

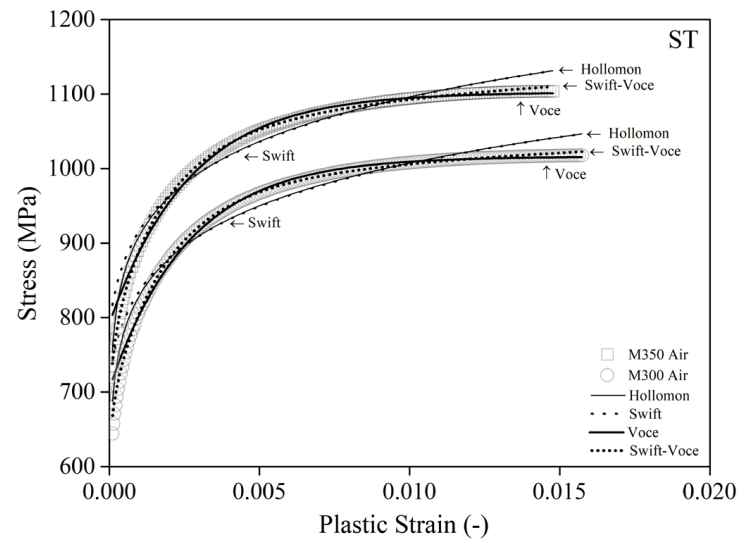

Figure 6. Curve fitting approach using different models for ST maraging steels by air environment.

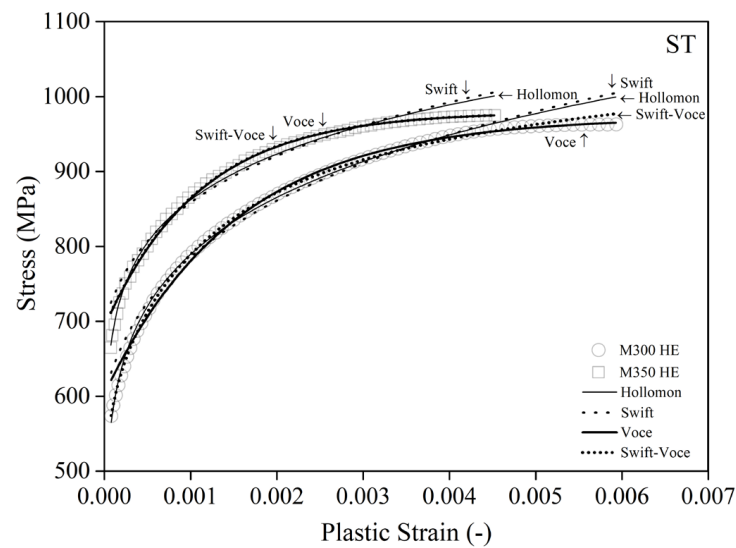

Figure 7. Curve fitting approach using different models for ST maraging steels by HE environment.

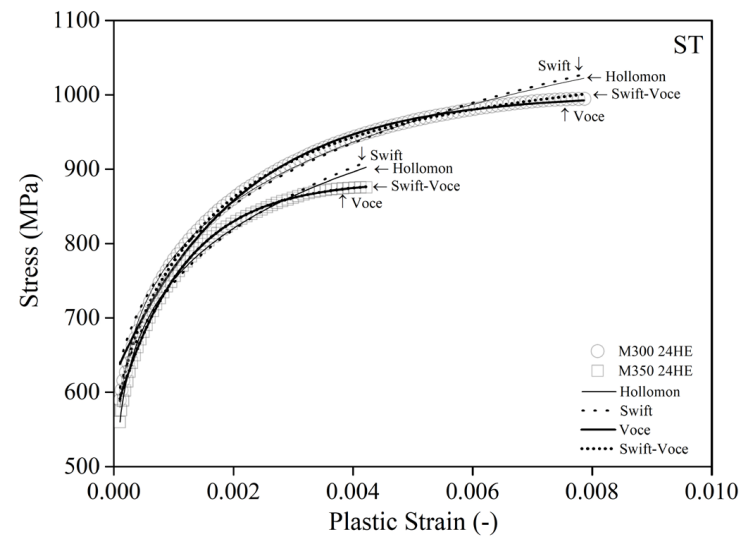

Figure 8. Curve fitting approach using different models for ST maraging steels by $24 \mathrm{HE}$ environment.

various studied conditions. Studies reported by Duc-Toan ${ }^{16}$ presented good results for Voce model to represent boron steel in different temperature ranges.

Studies reported by Mondal $^{24}$ presented the fitting curves of Hollomon, Swift and Voce for AFNOR 15CDV6 steel material. The model Voce described adequately the tensile flow behavior of the 15CDV6 steel subjected to cold deformation 
Table 4. Best fitting parameters of Hollomon, Swift, Voce and coupled Swift-Voce models for M300 and M350 in air, HE and 24HE condition.

\begin{tabular}{|c|c|c|c|c|c|c|c|c|c|}
\hline \multirow{2}{*}{ Specimens } & \multirow{2}{*}{ Model } & k & n & $\varepsilon_{o}$ & $\sigma_{S}$ & $\boldsymbol{R}_{o}$ & $R_{i n f}$ & b & $\alpha$ \\
\hline & & $M P a$ & - & $\mathrm{mm} / \mathrm{mm}$ & $M P a$ & $M P a$ & Mpa & - & - \\
\hline \multirow{4}{*}{ M300 Air } & Hollomon & 1485.66 & 0.084 & - & - & - & - & - & - \\
\hline & Swift & 1500.94 & 0.087 & 0.00 & - & - & - & - & - \\
\hline & Voce & - & - & - & 682.28 & 2497.27 & 300.88 & 494.17 & - \\
\hline & Swift-Voce & 1139.03 & 0.056 & 0.00 & 601.75 & 96.93 & 686.96 & 521.65 & 0.31 \\
\hline \multirow{4}{*}{ M350 Air } & Hollomon & 1591.4 & 0.081 & - & - & - & - & - & - \\
\hline & Swift & 1613.66 & 0.084 & 0.00 & - & - & - & - & - \\
\hline & Voce & - & - & - & 760.92 & 3570.02 & 296.84 & 524.80 & - \\
\hline & Swift-Voce & 1531.33 & 0.049 & 0.00 & 150.66 & 0.00 & 610.09 & 543.19 & 0.30 \\
\hline \multirow{4}{*}{ M300 HE } & Hollomon & 1973.19 & 0.133 & - & - & - & - & - & - \\
\hline & Swift & 2164.24 & 0.151 & 0.00 & - & - & - & - & - \\
\hline & Voce & - & - & - & 602.76 & 100.93 & 369.38 & 655.87 & - \\
\hline & Swift-Voce & 1172.29 & 0.080 & 0.00 & 608.89 & 101.08 & 1068.66 & 809.87 & 0.22 \\
\hline \multirow{4}{*}{ M350 HE } & Hollomon & 1707.66 & 0.099 & - & - & - & - & - & - \\
\hline & Swift & 1866.76 & 0.115 & 0.00 & - & - & - & - & - \\
\hline & Voce & - & - & - & 691.90 & 98.96 & 287.34 & 912.44 & - \\
\hline & Swift-Voce & 1292.52 & 0.149 & 0.396 & 739.28 & 99.56 & 1331.04 & 920.57 & 0.53 \\
\hline \multirow{4}{*}{$\begin{array}{l}\text { M300 } \\
24 \mathrm{HE}\end{array}$} & Hollomon & 1918.74 & 0.130 & - & - & - & - & - & - \\
\hline & Swift & 2057.21 & 0.144 & 0.000 & - & - & - & - & - \\
\hline & Voce & - & - & - & 619.78 & 101.16 & 379.98 & 490.89 & - \\
\hline & Swift-Voce & 1764.33 & 0.092 & 0.000 & 285.52 & 0.00 & 508.50 & 604.31 & 0.38 \\
\hline \multirow{4}{*}{$\begin{array}{l}\text { M350 } \\
24 \mathrm{HE}\end{array}$} & Hollomon & 1813.51 & 0.128 & - & - & - & - & - & - \\
\hline & Swift & 2062.62 & 0.151 & 0.000 & - & - & - & - & - \\
\hline & Voce & - & - & - & 564.06 & 236.08 & 318.56 & 894.85 & - \\
\hline & Swift-Voce & 847.98 & 0.141 & 0.222 & 1013.05 & 0.00 & 840.34 & 892.79 & 0.74 \\
\hline
\end{tabular}

Table 5. Coefficient of determination values for Hollomon, Swift, Voce and Swift-Voce coupled model after fitting curves.

\begin{tabular}{ccccc}
\hline \multirow{2}{*}{ Specimens } & \multicolumn{4}{c}{ coefficient of determination, $\mathbf{R}^{\mathbf{2}}$} \\
\cline { 2 - 5 } & Hollomon & Swift & Voce & Swift-Voce \\
\hline M300 Air & 0.9653 & 0.9453 & 0.9944 & 0.9987 \\
\hline M350 Air & 0.9744 & 0.9549 & 0.9933 & 0.9988 \\
\hline M300 HE & 0.9924 & 0.9766 & 0.9927 & 0.9988 \\
\hline M350 HE & 0.9908 & 0.9668 & 0.9920 & 0.9922 \\
\hline M300 24HE & 0.9930 & 0.9820 & 0.9935 & 0.9998 \\
\hline M350 24HE & 0.9917 & 0.9741 & 0.9966 & 0.9966 \\
\hline
\end{tabular}

by flow-forming, with fit providing the highest $\mathrm{R}^{2}$ results. The author also described the Voce model as being ideal for strength prediction, with its parameters correlated with $0.2 \%$ YS and UTS with similar slopes.

Coupled models, such as Swift-Voce, are also found in the literature with higher $\mathrm{R}^{2}$ values. A study reported by Sung ${ }^{31}$ presented the fitting of coupled Hollomon-Voce model with values of $\mathrm{R}^{2}$ up to 0.998 .

Therefore, for ST maraging steels M300 and M350, the Voce equation presents the best model to predict the strainhardening behavior in air and with $\mathrm{HE}$ and $24 \mathrm{HE}$ conditions, and it's aligned with the results reported by the literature.

\subsection{Generalized voce modeling by titanium approach}

Voce's model was chosen to get the generalized equation using Equation 18. Intermediate Voce curves between M300 ST and M350 ST results were obtained using a percentage of titanium mass by linear approach. The coefficients used were approximate for the functions that best describe their values in the variation of titanium composition in the alloy.

For M300-Air and M350-Air curves, simple linear functions are sufficient to represent the variation of these Voce parameters as a function of the titanium mass present. For the other conditions under hydrogen embrittlement, some coefficients obtained in the variation of titanium mass in the alloy favor the use of polynomial functions to better represent these parameters and mitigate the residual errors found.

The Table 6 presents the final parameters obtained as a function of mass titanium presented as disposed on Equation 14 to Equation 17. In general, the linear approximation is directly related to the hardening curves obtained from the specimens and its titanium contend. The polynomial terms presented on Table 6 reflects the approximation of the Voce parameters capable to determine the hardening models that represent this linear approach on stress-strain curves. In some coefficient 
parameters, as presented on MAAir condition in Table 6, linear terms are enough to represent correctly this approach.

\subsection{FEM results}

Using software ANSYS, it was possible to perform a simulation using the same boundary conditions performed on physical tensile tests. The generalized equations were used as input to represent the virtual specimens with the same dimensions as experimental tests. During element assignment, care was taken to ensure the quality of the mesh generated avoiding element distortion, void volumes and truncations. A comparison between the FEM analysis and the experimental results are presented on the Figure 9. The Table 7 presents the inputs used to describe the ST maraging steel in the software.

Table 6. Generalized Voce parameters as a function of the titanium contend present on ST maraging steels in air, HE and 24HE environment conditions.

\begin{tabular}{|c|c|c|}
\hline Material & Voce parameters & $f(T i)$ \\
\hline \multirow{4}{*}{ MA Air } & $\sigma_{S}(\mathrm{Ti})$ & $+111.1 * \mathrm{Ti}+601$ \\
\hline & $R_{o}(\mathrm{Ti})$ & $+1514.6 * \mathrm{Ti}+1392.4$ \\
\hline & $R_{\text {inf }}(\mathrm{Ti})$ & $-5.7 * \mathrm{Ti}+305$ \\
\hline & $\mathrm{b}(\mathrm{Ti})$ & $+43.2 * \mathrm{Ti}+462.4$ \\
\hline \multirow{4}{*}{ MA HE } & $\sigma_{S}(\mathrm{Ti})$ & $+125.9 * \mathrm{Ti}+510.7$ \\
\hline & $R_{o}(\mathrm{Ti})$ & $-12007 * \mathrm{Ti}^{2}+25907 * \mathrm{Ti}-12364$ \\
\hline & $R_{\text {inf }}(\mathrm{Ti})$ & $+74.65 * \mathrm{Ti}^{2}-276.9 * \mathrm{Ti}+531.6$ \\
\hline & $\mathrm{b}(\mathrm{Ti})$ & $+361.8^{*} \mathrm{Ti}+390.2$ \\
\hline \multirow{4}{*}{ MA 24HE } & $\sigma_{S}(\mathrm{Ti})$ & $-79 * \mathrm{Ti}+678$ \\
\hline & $R_{o}(\mathrm{Ti})$ & $-39671 * \mathrm{Ti}^{2}+85996 * \mathrm{Ti}-41481$ \\
\hline & $R_{\text {inf }}(\mathrm{Ti})$ & $+271.4 * \mathrm{Ti}^{2}-671.1 * \mathrm{Ti}+723.9$ \\
\hline & $\mathrm{b}(\mathrm{Ti})$ & $-241.16 * \mathrm{Ti}^{2}-1100.7 * \mathrm{Ti}-188.3$ \\
\hline
\end{tabular}

Table 7. Constants that determine the elastic isotropic and plastic isotropic region of each specimen for ST maraging steels used as input on ANSYS software.

\begin{tabular}{|c|c|c|c|c|c|c|}
\hline \multirow{2}{*}{ Specimens } & \multicolumn{2}{|c|}{ Linear elastic model } & \multicolumn{4}{|c|}{ Nonlinear plastic model - Voce } \\
\hline & $\mathbf{E}$ & poisson & $\sigma_{S}$ & $\mathbf{R}_{0}$ & $\mathbf{R}_{\mathrm{inf}}$ & b \\
\hline- & $G P a$ & - & $M p a$ & $M P a$ & $M p a$ & - \\
\hline M300 Air & 190 & 0.3 & 682.3 & 2497.3 & 300.9 & 494.17 \\
\hline M300 HE & 190 & 0.3 & 602.8 & 100.9 & 369.4 & 655.87 \\
\hline M300 24HE & 190 & 0.3 & 619.8 & 101.2 & 380.0 & 490.89 \\
\hline M350 Air & 200 & 0.3 & 760.9 & 3570.0 & 296.8 & 524.80 \\
\hline M350 HE & 200 & 0.3 & 691.9 & 99.0 & 287.3 & 912.44 \\
\hline M350 24HE & 200 & 0.3 & 564.1 & 236.1 & 318.6 & 894.85 \\
\hline
\end{tabular}

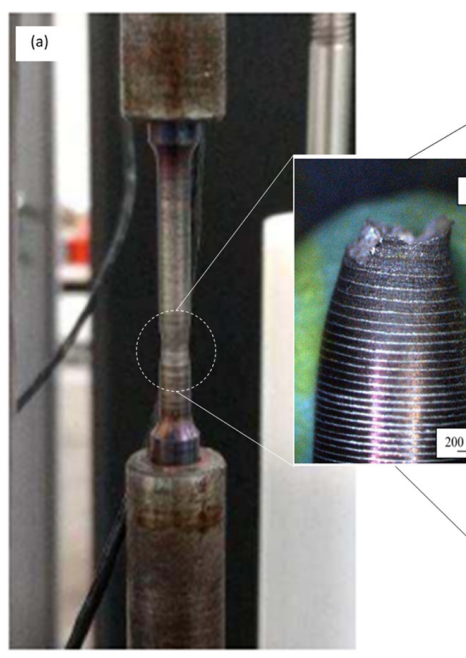

FEM RESULTS

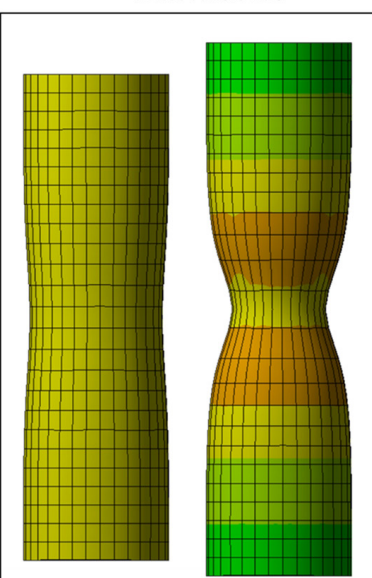

(c)

Figure 9. (a) SSRT performed for M350 with (b) a neck formation on the material and (c) results of a numerical simulation using Voce parameters for predict the strain-hardening behavior. 
The results obtained and their post-processing are compared with the results presented experimentally following numerical validation steps. It was possible to observe, during its numerical test, the presence of an instability point (necking) in the virtual specimen. When compared with the physical tests, it's noted the same strain-hardening behavior, with the presence of necking in the same level of stress $(1097 \pm 12 \mathrm{MPa})$.

Duc-Toan $^{16}$, in his work, also used the Voce model to represent boron steel in different temperature ranges, presenting good comparability between the simulation results and the corresponding experiments.

The numerical validation procedure was performed for the other curves obtained for the ST maraging M300 and M350 steels under their different environment conditions. The deviations found between physical test and numerical analysis were very similar and the accuracy of the values obtained presented a small average error of less than $0.5 \%$ until the necking formation. The generalized equations presented in this paper provided a good predicting results for ST maraging steels in air and in hydrogen embrittlement environments performed with a satisfactory numerical validation.

\section{Conclusions}

From SSRT, it was observed that the M350 ST steel tested in the air presented $9 \%$ of higher UTS, as well as, lower elongation (8\%) and reduction of area (14\%), when compared by M300 ST in the same air condition. The tests performed on electrolytic cells showed a drop in mechanical strength of $9 \%$ (HE) and $18 \%$ (24HE) for the M350 and less than $2 \%$ (HE and 24HE) for M300. Therefore, the M350 showed more significant weaknesses than M300 steel, showing the deleterious effect of the presence of hydrogen, being intensified with the greater exposure of the material to the fragilizing environment.

Fractography showed the presence of dimples with cone cup formation in the air tested condition for both steels, being clearer for the M300. As well, it presented in both specimens the characteristic of mixed fracture after SSRT in a rich hydrogen environment, with formation of cleavage facets and the presence of inter and trans granular cracks. These results can be correlated with the greater presence of chemical elements, such as Ti, dissolved in solid solution, making it difficult to move disagreements and acting as trapping for hydrogen.

The curve fitting was performed and provided the best coefficients to predict the M300 and M350 ST specimens for Hollomon, Swift, Voce and coupled Swift-Voce models. The fit results showed that Hollomon and Swift equations can describe satisfactory the strain-behavior, with values of $\mathrm{R}^{2}$ between 0.945 to 0.993 . The coupled Swift-Voce model presented higher coefficient of determination $\mathrm{R}^{2}$, with values up to 0.992 but similar to results reported by Voce model. The fit results obtained were aligned with the literature and concludes the Voce model provides more accurate predictions at large stress-strain behavior represented until the necking formation on a typical ductile fracture.

The generalized Voce model by the titanium approach also met the proposed objective, presenting the equations that can linearly describe the behavior of the material as a function of the titanium content in the alloy.

Using ANSYS software, the SSRT was performed numerically with same boundary conditions as well the strainhardening models used to predict the material behavior. The FEA results were compared with bench tests, validating the accuracy of the predicted models. Finally, the coefficients determined in this paper can be used to perform numerical simulations and meet the needs of the engineering application.

\section{References}

1. Sirin S, Sirin K, Kaluc E. Effect of the ion nitriding surface hardening process on fatigue behavior of AISI 4340 steel. Mater Charact. 2008;59(4):351.

2. Meinhardt C, Scheid A, Santos J. Hydrogen embrittlement under cathodic protection of friction stir welded UNS S32760 super duplex stainless steel. Mater Sci Eng A. 2017;706:48.

3. Barsanti M, Beghini M, Frasconi F, Ishak R, Monelli B, Valentini R. Experimental study of hydrogen embrittlement in Maraging steels. Procedia Struct. Integr. 2018;8:501.

4. Santos LPM, Béreš M, Bastos IN, Tavares SSM, Abreu HFG, Gomes da Silva MJ. Hydrogen embrittlement of ultra high strength 300 grade maraging steel. Corros Sci. 2015;101:12.

5. Valentini R, Colombo C, De Sanctis M, Lovicu G. Hydrogen re-embrittlement of aerospace grade high strength steels. Frat. ed Integrita Strutt. 2012;6(21):30-36.

6. Padial A. Transformações de fase e propriedades mecânicas de um aço maraging sem cobalto [dissertation]. São Paulo: Instituto de Pesquisas Energéticas e Nucleares; 1994.

7. Dossett JL, Totten GE. Heat Treat of Irons and Steels. Materials Park, OH: ASM International; 2018. p. 468-80.

8. Pound BG. Hydrogen trapping in precipitation-hardened alloys. Acta Metall Mater. 1990;38(12):2373

9. Tsay LW, Chi MY, Wu YF, Wu JK, Lin DY. Hydrogen embrittlement susceptibility and permeability of two ultra-high strength steels. Corros Sci. 2006;48(8):1926.

10. Tsay LW, Lu HL, Chen C. The effect of grain size and aging on hydrogen embrittlement of a maraging steel. Corros Sci. 2008;50(9):2506.

11. Men'shikova I, Shimelevich L, Getmanskaya G. Effect of titanium on the mechanical properties of maraging steel N18K8M5T. Maraging Steels. 1969;11(4):251.

12. Huang CQ, Deng J, Wang SX, Liu L. A Physical-based constitutive model to describe the strain-hardening and dynamic recovery behaviors of 5754 aluminum alloy. Mater Sci Eng A. 2017;699:106

13. Nieto-Fuentes JC, Rittel D, Osovski S. On a dislocation-based constitutive model and dynamic thermomechanical considerations. Int J Plast. 2018;108(February):55

14. LeMaitre J. Handbook of materials behavior models. 1st ed. Cachan Cedex: Academic Press; 2001.

15. Sha W, Guo Z. Maraging steels: modelling of microstructure. 1st ed. Properties and Applications; 2009.

16. Duc-Toan N, Tien-Long B, Dong-Won J, Seung-Han Y, YoungSuk K. A modified Johnson-Cook model to predict stress-strain curves of boron steel sheets at elevated and cooling temperatures. High Temp. Mater. Process. 2015;31(1):37.

17. Kohnke P. ANSYS Theory Reference - Release 5.6. Canonsburg, PA: SAS IP, Inc.; 1999. http://research.me.udel.edu/ lwang/ teaching/MEx81/ansys56manual.pdf.

18. Swift HW. Plastic instability under plane stress. J Mech Phys Solids. 1952;1(1): 1 .

19. Naranjo J, Miguel V, Martínez A, Coello J, Manjabacas MC. Analysis of material behavior models for the Ti6Al4V alloy to simulate the Single Point Incremental Forming process. Procedia Manuf. 2017;13:307. 
20. Sung JH, Kim JH, Wagoner RH. A plastic constitutive equation incorporating strain, strain-rate, and temperature. Int J Plast. 2010;26(12):1746.

21. Mahalle G, Salunke O, Kotkunde N, Gupta A, Singh S. Neural network modeling for anisotropic mechanical properties and work hardening behavior of Inconel 718 alloy at elevated temperatures. J. Mater. Res. Technol. 2019;8(2):2130.

22. Gomes F, Pereira F, Marins F, Silva M. Comparative study between the generalized reduced gradient and genetic algorithm in multiple response optimization. Produção Online. 2017;17:592.

23. Kwesi Nutor R. Using the hollomon model to predict strainhardening in metals. Am. J. Mater. Synth. Process. 2017;2(1):1.

24. Mondal C, Podder B, Ramesh Kumar K, Yadav DR. Constitutive description of tensile flow behavior of cold flow-formed AFNOR 15CDV6 steel at different deformation levels. J Mater Eng Perform. 2014;23(10):3586.

25. Levitas VI, Roy AM. Multiphase phase field theory for temperature - and stress-induced phase transformations. Phys Rev B Condens Matter Mater Phys. 2015;91(17):1.

26. Levitas VI, Roy AM, Preston DL. Multiple twinning and variantvariant transformations in martensite: phase-field approach. Phys Rev B Condens Matter Mater Phys. 2013;88(5):1.

27. He X, Yao Y. A dislocation density based viscoplastic constitutive model for lead free solder under drop impact. Int J Solids Struct. 2017;120:236.

28. Solomon ELS, Natarajan AR, Roy AM, Sundararaghavan V, Van der Ven A, Marquis EA. Stability and strain-driven evolution of $\beta^{\prime}$ precipitate in Mg-Y alloys. Acta Mater. 2019;166:148.

29.ASTM International. G129-00(2013), Standard practice for slow strain rate testing to evaluate the susceptibility of Metallic Materials to Environmentally Assisted Cracking. West Conshohocken, PA: ASTM International; 2013.
30. Sha W, Guo Z. Maraging Steels: Modelling of Microstructure, Properties and Applications, 1st ed. Guildford, UK: Woodhead Publishing; 2009. https://doi.org/10.1533/9781845696931.

31. Sung JH, Kim JH, Wagoner RH. A plastic constitutive equation incorporating strain, strain-rate, and temperature. Int J Plast. 2010;26(12):1746.

32. Pardal JM, Tavares SSM, Tavares MT, Garcia PSP, Velasco JAC, Abreu HFG, et al. Influence of carbon content on the martensitic transformation of titanium stabilized austenitic stainless steels. Int J Adv Manuf Technol. 2020;108(1-2):345.

33. Viswanathan UK, Dey GK, Sethumadhavan V. Effects of austenite reversion during overageing on the mechanical properties of 18 Ni (350) maraging steel. Mater Sci Eng A. 2005;398(1-2):367.

34. Chakravarthi K, Koundinya N, Narayana Murty S, Nageswara R. Microstructure, properties and hot workability of M300 grade maraging steel. Def. Technol. 2018;14(1):51.

35. Dos Reis AG, Reis DAP, Abdalla AJ, Couto AA, Otubo J. Short-term creep properties and fracture surface of $18 \mathrm{Ni}(300)$ maraging steel plasma nitrided. Mater Res. 2017;20(300):2.

36. Wang G, Yan Y, Li J, Huang J, Qiao L, Volinsky AA. Microstructure effect on hydrogen-induced cracking in TM210 maraging steel. Mater Sci Eng A. 2013;586:142.

37. Gomes FM, Pereira FM, Marins FAS, Silva MB. Estudo comparativo entre os métodos gradiente reduzido generalizado e algoritmo genético em otimização com múltiplas respostas. Rev. Produção Online. 2017;17(2):592.

38. Cao J, LIFG, MAXK, SUN ZK Tensile stress-strain behavior of metallic alloys. Trans. Nonferrous Met. Soc. China. 2017;27(11): 2443-53.

39. Vadayar KS, Mehta KK, Prasad L. Constitutive flow stress model of maraging steels in cold flow formed and aged conditions. 2019;14(4):1041. 